\title{
Determination of $\mathrm{pK}_{\mathrm{a}}$ Values for Acrylic, Methacrylic and Itaconic Acids by ${ }^{1} \mathrm{H}$ and ${ }^{13} \mathrm{C}$ NMR in Deuterated Water
}

\author{
Emma Lilia Ibarra-Montaño ${ }^{1}$, Norma Rodríguez-Laguna ${ }^{2}$, Aníbal Sánchez-Hernández ${ }^{2}$ and \\ Alberto Rojas-Hernández ${ }^{2, *}$
}

${ }^{1}$ CIP, S.A. de C.V., Marcos Achar Lobaton No 2, Tepexpan Municipio Acolman de Nezahualcóyotl, CP 55885 Estado de México, Mexico

${ }^{2}$ Universidad Autónoma Metropolitana-Iztapalapa, Depto. de Química, Área de Química Analítica, San Rafael Atlixco 186, Col. Vicentina, CP 09340 México, D. F., Mexico

\begin{abstract}
Acrylic, methacrylic and itaconic acids have Brønsted acidity given by carboxylic groups, and they are extensively used in polymerization for modification of several soft-mater materials. By this reason it is important to propose better characterization studies and alternatives to obtain more of their physicochemical properties. In this work the $\mathrm{pK}_{\mathrm{a}}$ values of these acids are obtained by adjusting NMR chemical shifts for hydrogen and carbon nuclei as a function of $\mathrm{pH}$ with program HYPNMR, and compared with those obtained by potentiometric and conductometric titrations.
\end{abstract}

Keywords: $\mathrm{pK}_{\mathrm{a}}$ values, acrylic acid derivatives, HYPNMR, ${ }^{1} \mathrm{H}$ NMR, ${ }^{13} \mathrm{C}$ NMR.

\section{INTRODUCTION}

Unsaturated carboxylic acids are used to increase the solubility in water of several substances or confer it some specific properties by polymerization [1-6].

Some of these substances, preferred by its small size, are acrylic (AA), methaclrylic (MA) and itaconic acids (IA). The developed formulae of these substances are given in Figure $\mathbf{1}$.

Recently some papers have reported the use of NMR to determine pKa values of drugs, like an alternative to other methods [7, 8]. This task could help to give, at the same time, structural information to characterize better the substances in other fields of research and industry.

The aim of the present work is to show the easiness of the NMR technique to determine pKa values for very soluble substances in water and compare it with those obtained with potentiometric and conductometric methods.

\section{MODELING}

\subsection{Chemical Shifts of NMR Curves to Determine $\mathrm{pK}_{\mathrm{a}}$ Values}

The protonation degree of a molecule has an effect over the chemical shifts of different nuclei of the

*Address correspondence to this author at the Universidad Autónoma Metropolitana-Iztapalapa, Depto. de Química, Area de Química Analítica, San Rafael Atlixco 186, Col. Vicentina, CP 09340 México, D.F, Mexico;

Tel: 5255-5804-4670; Fax: 5255-5804-4666;

E-mail: suemi918@xanum.uam.mx molecule, which permit to obtain sigmoidal curves of chemical shift as a function of $\mathrm{pH}$ for each nucleus.

The inflexion point of a sigmoidal curve may be related with a $\mathrm{pK}_{\mathrm{a}}$ value for the simplest cases where there is only one acidity equilibrium, which is the case of $A A$ and $M A$, in agreement with the Equation 1.

${ }_{X_{i}} \delta_{L^{\prime}}=f_{L}\left({ }_{X_{i}} \delta_{L}\right)+f_{H L}\left({ }_{X_{i}} \delta_{H L}\right)$

where $X_{i}$ represent the nucleus ( $\mathrm{H}$ or $\mathrm{C}$ in this case) in the $i$-esim position of the molecule for $i \in\{1,2, \ldots, n\}$ and $n$ the number of active nuclei; $L$ and $H L$ represent the deprotonated and protonated species of the substance, respectively; $f_{L}$ and $f_{H L}$ represent the molar fractions of $L$ species (Equation 2); and $L^{\prime}$ takes in account all the $\mathrm{L}$ species with different protonation degrees in the system [8]. Electrical charges will be omitted in equations to simplify notation.

$f_{L} \equiv \frac{[L]}{\left[L^{\prime}\right]}=\frac{[L]}{[L]+[H L]}=\frac{1}{1+10^{\left(\mathrm{pK}_{\mathrm{a}}-\mathrm{pH}\right)}}$

$f_{H L} \equiv \frac{[H L]}{\left[L^{\prime}\right]}=f_{L} \frac{\left[H^{+}\right]}{\mathrm{K}_{\mathrm{a}}}=\frac{10^{\left(\mathrm{pK}_{\mathrm{a}}-\mathrm{pH}\right)}}{1+10^{\left(\mathrm{pK}_{\mathrm{a}}-\mathrm{pH}\right)}}$

Equations 1 and 2, for each nucleus, may be used to fit experimental sigmoidal curves with a non-linear regression method to determine the $\mathrm{pK}_{\mathrm{a}}$ value of the species $H L$.

Nevertheless, for cases in which there are two or more acid-base equilibria, theoretically there are several inflexion points, which not necessarily 


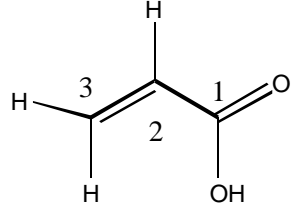

Acrylic acid (AA)

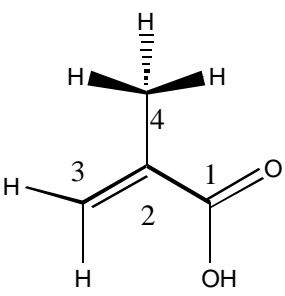

Methacrylic acid (MA)

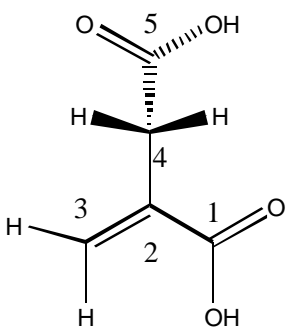

Itaconic acid (IA)

Figure 1: Developed formulae for the carboxylic acids studied in this work with numbering to each nucleus or set of nuclei.

correspond to $\mathrm{pK}_{\mathrm{a}}$ values in the $\mathrm{pH}$ scale. For example, $\mathrm{IA}$ is a di-carboxylic acid with $\mathrm{pK}_{\mathrm{a}}$ values separated by less of two units [9]. The kind of sigmoidal curves of chemical shifts of their nuclei as a function of $\mathrm{pH}$ are described by equations 3 and 4 .

$$
{ }_{X_{i}} \delta_{L^{\prime}}=f_{L}\left({ }_{X_{i}} \delta_{L}\right)+f_{H L}\left({ }_{X_{i}} \delta_{H L}\right)+f_{H_{2} L}\left({ }_{X_{i}} \delta_{H_{2} L}\right)
$$

Then, the fitting of sigmoidal curves for the nuclei in the different species of the system, by a non-linear regression method, can be used to determine $\mathrm{pK}_{\mathrm{a} 1}$ and $\mathrm{pK}_{\mathrm{a} 2}$ values -even though the inflexion points do not correspond with $\mathrm{pK}_{\mathrm{a}}$ values.

$$
\begin{aligned}
& f_{L} \equiv \frac{[L]}{\left[L^{\prime}\right]}=\frac{[L]}{[L]+[H L]+\left[H_{2} L\right]}=\frac{1}{1+10^{\left(\mathrm{pK}_{\mathrm{a} 2}-\mathrm{pH}\right)}+10^{\left(\mathrm{pK}_{\mathrm{a} 1}+\mathrm{pK}_{\mathrm{a} 2}-2 \mathrm{pH}\right)}} \\
& f_{H L} \equiv \frac{[H L]}{\left[L^{\prime}\right]}=f_{L} \frac{\left[H^{+}\right]}{\mathrm{K}_{\mathrm{a} 2}}=\frac{10^{\left(\mathrm{pK}_{\mathrm{a} 2}-\mathrm{pH}\right)}}{1+10^{\left(\mathrm{pK}_{\mathrm{a} 2}-\mathrm{pH}\right)}+10^{\left(\mathrm{pK}_{\mathrm{a} 1}+\mathrm{pK}_{\mathrm{a} 2}-2 \mathrm{pH}\right)}} \\
& f_{H_{2} L} \equiv \frac{\left[H_{2} L\right]}{\left[L^{\prime}\right]}=f_{L} \frac{\left[H^{+}\right]^{2}}{\mathrm{~K}_{\mathrm{a} 1} \mathrm{~K}_{\mathrm{a} 2}}=\frac{10^{\left(\mathrm{pK}_{\mathrm{a} 1}+\mathrm{pK}_{\mathrm{a} 2}-2 \mathrm{pH}\right)}}{1+10^{\left(\mathrm{pK}_{\mathrm{a} 2}-\mathrm{pH}\right)}+10^{\left(\mathrm{pK}_{\mathrm{a} 1}+\mathrm{pK}_{\mathrm{a} 2}-2 \mathrm{pH}\right)}}
\end{aligned}
$$

The method explained in this subsection is that used in the present work, using HYPNMR program [8, $10,11]$ to fit simultaneously all the sigmoidal curves useful to determine $\mathrm{pK}_{\mathrm{a}}$ values.

\subsection{Potentiometric Titration Curves to Determine pKa Values}

In order to fit the $\mathrm{pH}$-metric titration curves is common to use a robust model, in which the volume is calculated for any $\mathrm{pH}[12,13]$.

$A$ valid equation to fit $A A$ or $M A$ pH-metric curves is presented in Equation 5.

$$
V_{\mathrm{NaOH}}=\frac{-V_{o} C_{o}\left[f_{L}\right]-V_{o}\left(\left[\mathrm{H}^{+}\right]-\frac{K_{w}}{\left[\mathrm{H}^{+}\right]}\right)}{C_{\mathrm{NaOH}}+\left[\mathrm{H}^{+}\right]-\frac{K_{w}}{\left[\mathrm{H}^{+}\right]}}
$$

where $f_{L}$ is the molar fraction of the acrylate or methacrylate ion in agreement with Equation 2, $\mathrm{V}_{\mathrm{NaOH}}$ is the added volume and $C_{\mathrm{NaOH}}$ the molar concentration of sodium hydroxide used as titrant, $V_{o}$ is the initial volume and $C_{o}$ the molar analytical concentration of $\mathrm{AA}$ or MA to be titrated, $K_{w}$ is the autoprotolysis constant of water and $\left[\mathrm{H}^{+}\right]=10^{-\mathrm{pH}}$.

A valid equation to fit $\mathrm{IA} \mathrm{pH}$-metric curves is presented in Equation 6.

$V_{\mathrm{NaOH}}=\frac{-V_{o} C_{o}\left[2 f_{L}+f_{\mathrm{HL}}\right]-V_{o}\left(\left[\mathrm{H}^{+}\right]-\frac{K_{w}}{\left[\mathrm{H}^{+}\right]}\right)}{C_{\mathrm{NaOH}}+\left[\mathrm{H}^{+}\right]-\frac{K_{w}}{\left[\mathrm{H}^{+}\right]}}$

where $f_{L}$ and $f_{H L}$ are the molar fractions of the itaconate and itaconate acid ions in agreement with Equation 4, and the other symbols have the same meaning that for Equation 5.

In order to determine $\mathrm{pK}_{\mathrm{a}}$ values by means of $\mathrm{pH}$ metric curves the program SUPERQUAD [14] has been used.

\subsection{Conductometric Fitting of Titration Curves}

It is less common to use conductometric titration curves in order to determine $\mathrm{pK}_{\mathrm{a}}$ values. Nevertheless, the conductivity of solutions of $\mathrm{AA}$ or MA (in mixture with $\mathrm{HCl}$ ) during titration may be written like is given in Equation 7.

$$
\begin{aligned}
& \kappa=\lambda_{\mathrm{H}^{+}}\left[\mathrm{H}^{+}\right]+\lambda_{\mathrm{OH}^{-}} \frac{K_{w}}{\left[\mathrm{H}^{+}\right]}+\frac{V_{o} C_{o}}{V_{o}+V_{\mathrm{NaOH}}}\left(\lambda_{L} f_{L}\right)+ \\
& \lambda_{\mathrm{Na}} \frac{V_{\mathrm{NaOH}} C_{\mathrm{NaOH}}}{V_{o}+V_{\mathrm{NaOH}}}+\lambda_{\mathrm{Cl}} \frac{V_{o} C_{\mathrm{HCl}}}{V_{o}+V_{\mathrm{NaOH}}}
\end{aligned}
$$

where $\lambda_{\mathrm{H}^{+}}, \lambda_{\mathrm{OH}^{-}}, \lambda_{\mathrm{Na}}$ and $\lambda_{\mathrm{L}}$ are the equivalent conductivities of hydronium, hydroxide, sodium and acrylate or methacrylate ions, respectively.The other 
symbols have the same meaning that they have in Equations 2 and 5.

In the same way, the conductivity of solutions of IA during titration may be written like it is shown in Equation 8.

$\kappa=\lambda_{\mathrm{H}^{+}}\left[\mathrm{H}^{+}\right]+\lambda_{\mathrm{OH}^{-}} \frac{K_{w}}{\left[\mathrm{H}^{+}\right]}+\frac{V_{o} C_{o}}{V_{o}+V_{\mathrm{NaOH}}}\left(2 \lambda_{L} f_{L}+\lambda_{\mathrm{HL}} f_{\mathrm{HL}}\right)+$

$+\lambda_{\mathrm{Na}} \frac{V_{\mathrm{NaOH}} C_{\mathrm{NaOH}}}{V_{o}+V_{\mathrm{NaOH}}}$

where $\lambda_{L}$ and $\lambda_{H L}$ are the equivalent conductivities of itaconate and itaconate acid ions, respectively. The other symbols have the same meaning that they have in Equations 4 and 6.

Then, conductometric titrations for $A A$ or $M A$ solutions may be fitted by using the Equations 2, 5 and
7; while for the fitting of IA conductometric titrations Equations 4, 6 and 8 should be used.

\section{RESULTS AND DISCUSSION}

\subsection{NMR}

Figure 2 presents ${ }^{1} \mathrm{H}$ NMR spectra of $A A$ in acid and basic media, showing that chemical shift of several nuclei depends on $\mathrm{pH}$. Additionally the assignation of signals to each nucleus could be easily achieved when there is multiplicity, which could be explained by the structure of molecule. In the case of AA, the signals observed are known as doublet of doublets [15] because each hydrogen nucleus of the vinyl group is coupled with the other two of the same group. Then, there is a strong coupling among the hydrogen nuclei placed in both sides of double bond followed by a weak coupling among geminal hydrogen nuclei. Also for that reason $M A$ and $I A{ }^{1} H$ NMR spectra have only single

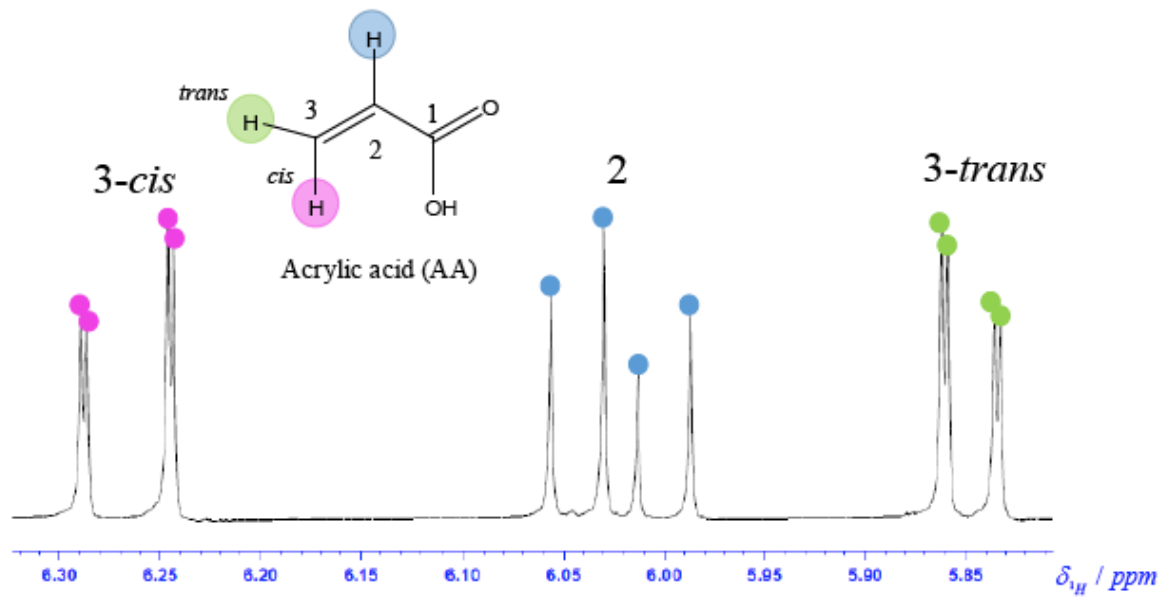

(a)

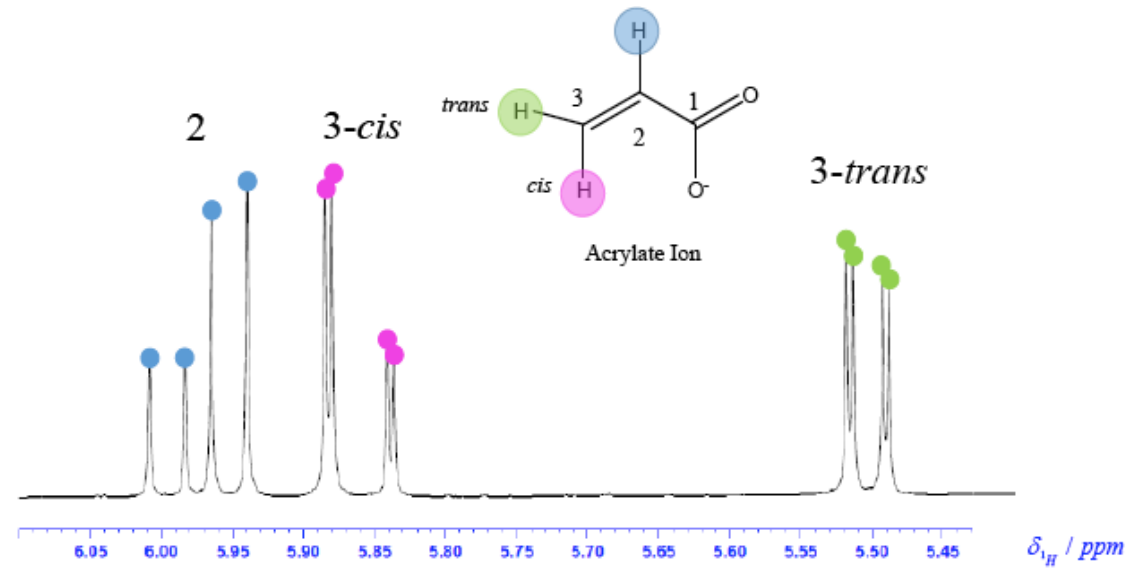

(b)

Figure 2: ${ }^{1} \mathrm{H}$ NMR spectra for $\mathrm{AA}$ in $\left.\mathbf{a}\right) \mathrm{pH}=1.28$ and $\left.\mathbf{b}\right) \mathrm{pH}=12.45$. The signals of each hydrogen nucleus are a doublet of doublets (or double of doubles). 
signals. From Figure 2, it can be shown that the signal of the hydrogen in position 2 of $A A$ is practically independent on $\mathrm{pH}$.

Sets of spectra of hydrogen and carbon as a function of $\mathrm{pH}$ have been obtained for the three carboxylic acids studied in the present work.

Like an example, Figure 3 shows the dependence of the signals of carbon nuclei with $\mathrm{pH}$ with the aid of some ${ }^{13} \mathrm{C}$ NMR spectra of the set obtained for MA.

It is clear (Figure 3) that the carbon signals of methyl group of MA (or those of methylene group of IA) are less dependent on $\mathrm{pH}$ than the others.

The chemical shift values of the nuclei of carboxylic acids studied in the present work are presented in Table $\mathbf{1}$ at acid and basic $\mathrm{pH}$ values.

Like an example of sigmoidal curves that may be obtained, Figure 4 shows the chemical shifts as a function of $\mathrm{pH}$ for the carbon nucleus of carboxylate ion in position 1 of the molecules for $A A, M A$ and IA. Markers represent experimental points while solid lines represent the fitting with the corresponding model using data of Table 2 for AA and MA, and of Table 3 (Model I) for IA. It is evident that the model of one acid-base equilibrium is not enough adequate for IA, because the residuals show a trend: the calculated points in the model before inflexion point are greater than the experimental ones, but after inflexion point the calculated points are lesser.
Although one of this kind of curves may be used to obtain an estimator of $\mathrm{pK}_{\mathrm{a}}$ value, statistically is better fitting simultaneously all the sigmoidal curves useful for the same group of experiments. This has been achieved for AA, MA and IA with program HYPNMR. Like an example, Figure 5 shows all the fitted curves for IA with Model II.

Tables $\mathbf{2}$ and $\mathbf{3}$ show that better results for the fit are obtained when more points are used with the more meaningful model for $A A, M A$ and IA, as well as the good agreement with $\mathrm{pK}_{\mathrm{a}}$ values previously reported. Figure 5 shows the very good fitting achieved of the experimental data for the case of IA.

In order to compare the quality of $\mathrm{pK}_{\mathrm{a}}$ values obtained by NMR, potentiometric and conductometric titrations have been obtained.

\subsection{Potentiometry and Conductometry}

The potentiometric titrations (with an automatic titrator for $\mathrm{AA}$ and $\mathrm{MA}$ and manual for $\mathrm{IA}$ ) are shown in Figures $\mathbf{6 a}, \mathbf{7 a}$ and $\mathbf{8 a}$, respectively. More points have been acquired when an automatic titrator has been used, as expected.

The shape of $A A$ and MA titrations is that expected for monoprotic acids, with a titration reaction very quantitative (Figures 6a and 7a).

The IA titration also has the expected shape for a diprotic acid, with pKa values near one of each other, for which the first titration reaction is few quantitative and the second is very quantitative (Figure 8a).

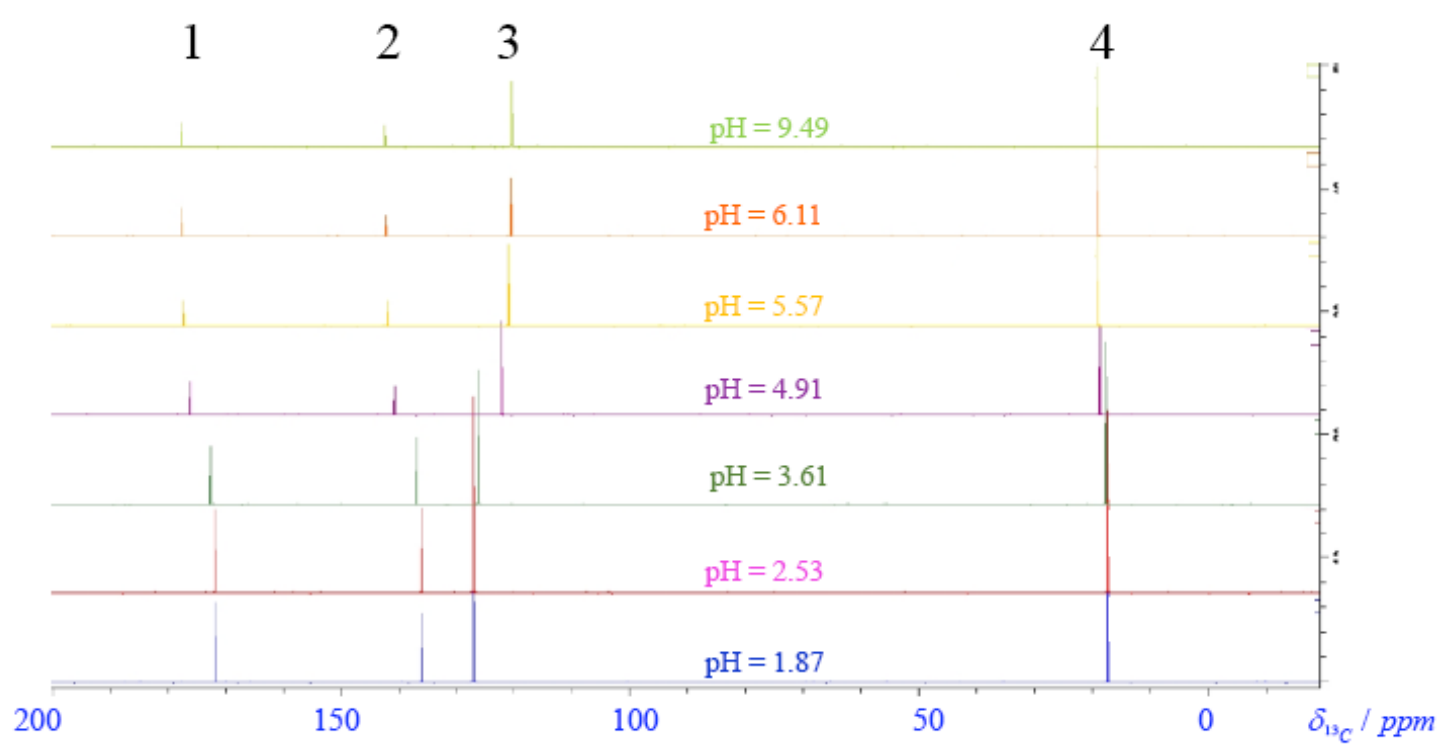

Figure 3: ${ }^{13} \mathrm{C}$ NMR spectra for MA at several $\mathrm{pH}$ values.Numbers in top of figure indicate the position of the carbon atom in the developed formulae. 
Table 1: NMR Chemical Shifts for Hydrogen and Carbon Nuclei of Different Carboxylic Acids Studied in this Paper, in Acid and Basic Media

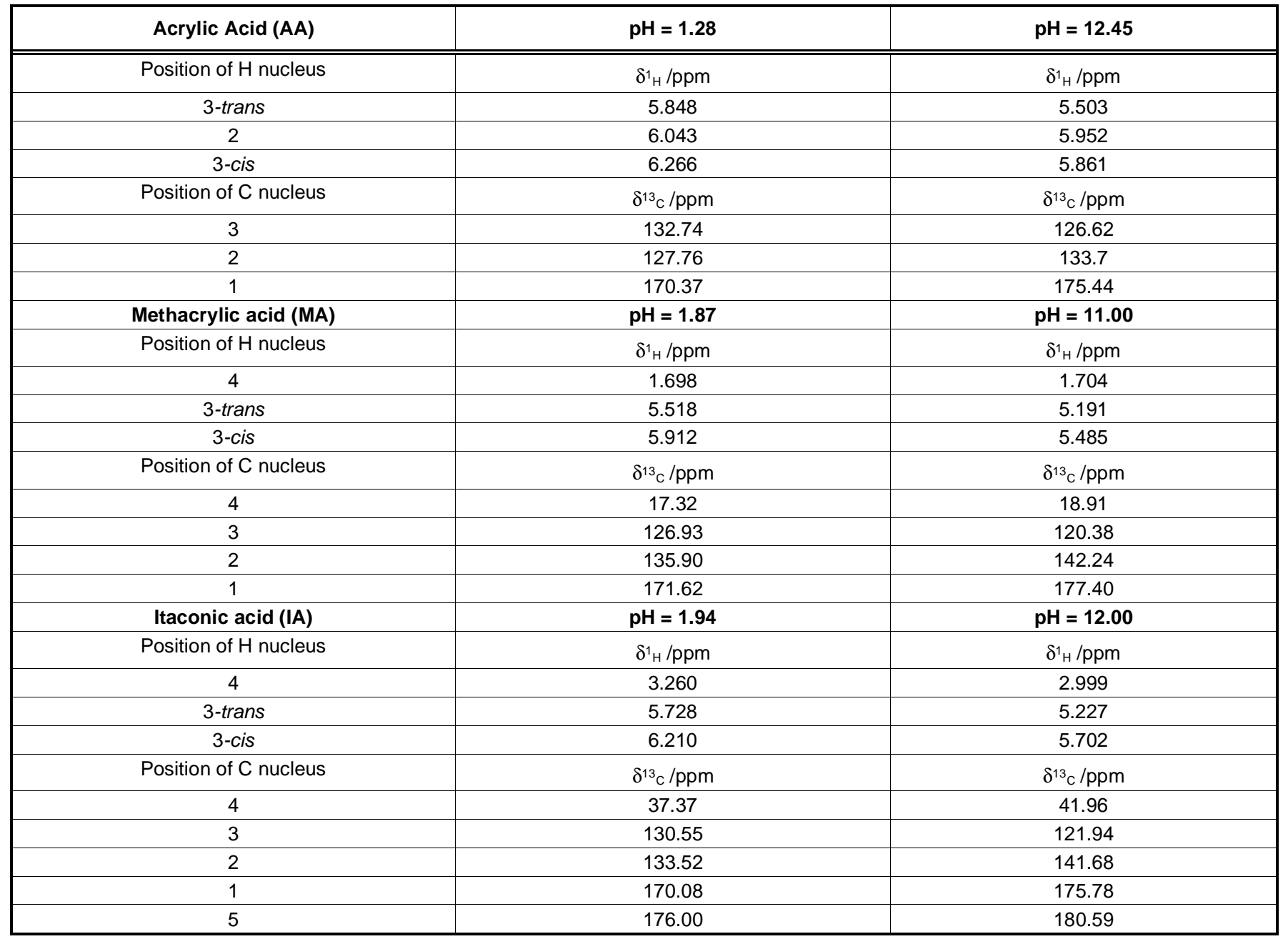
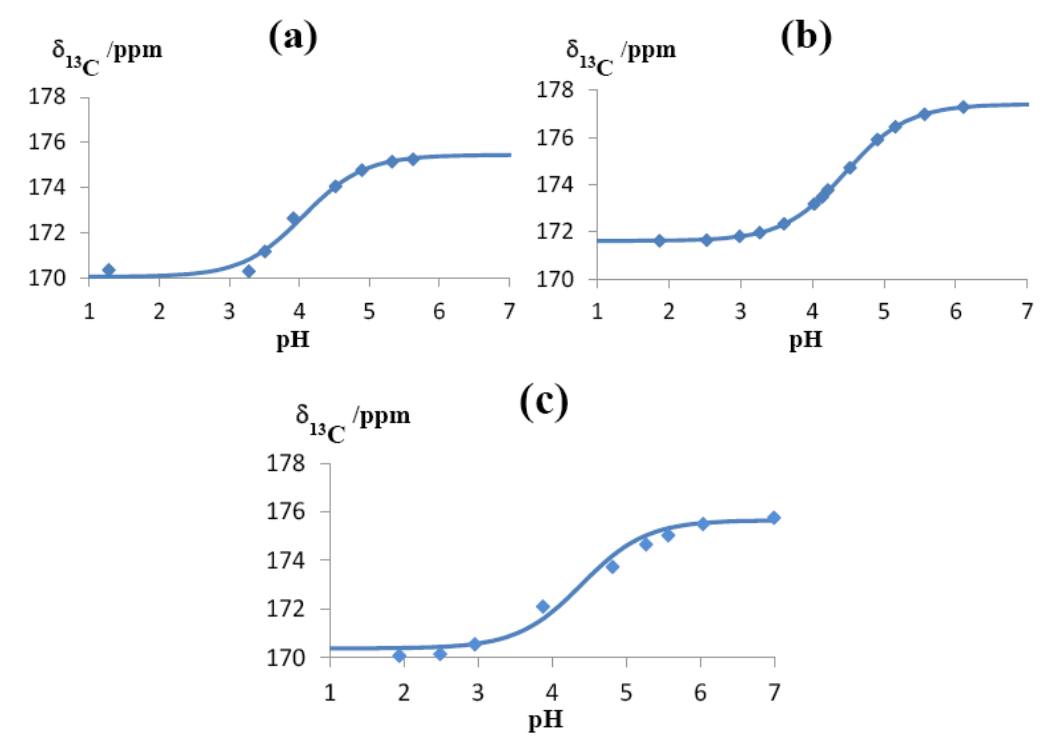

Figure 4: Chemical shifts of carbon nucleus of carboxylate group 1 as a function of $\mathrm{pH}$ for: a) AA. b) MA. c) IA. Markers represent experimental data and solid line is calculated with a model of one equilibrium of acidity with the parameters shown in Table 2, for AA and MA, and in Table 3, Model I, for IA. 


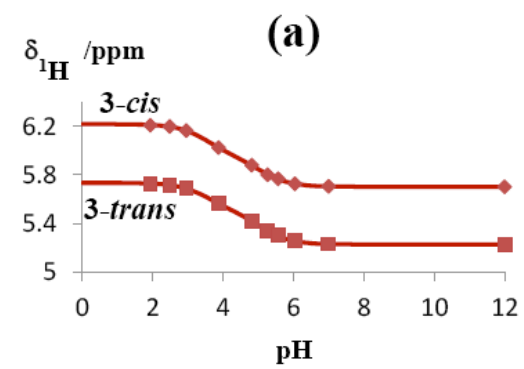

(c)
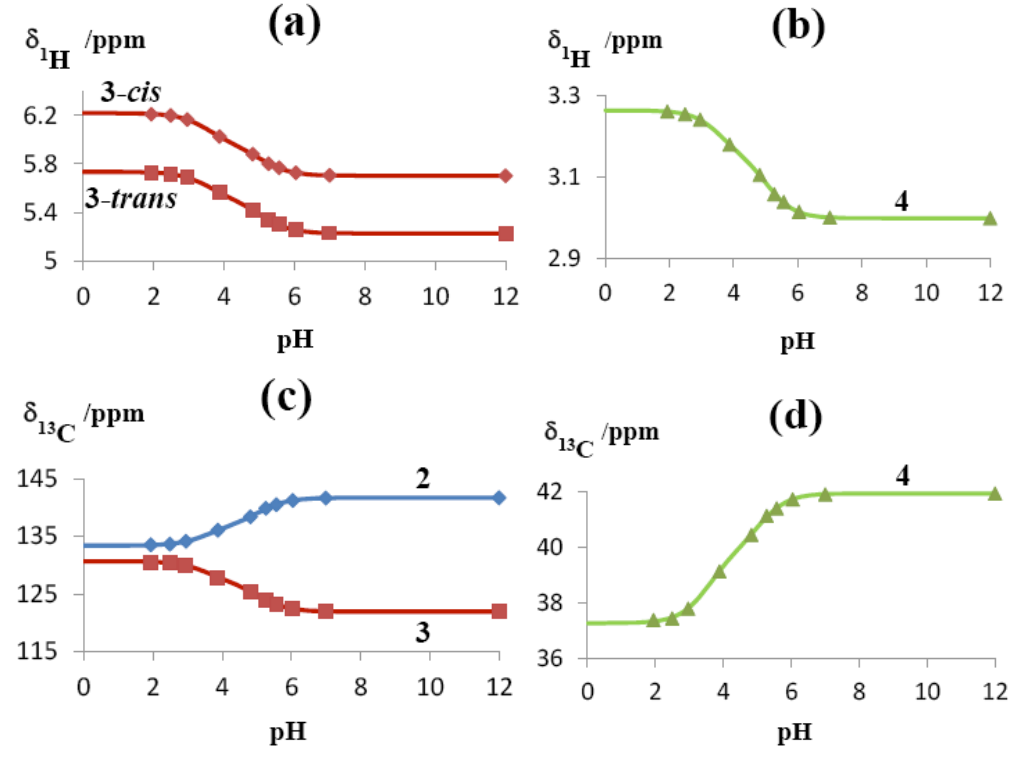

(e)

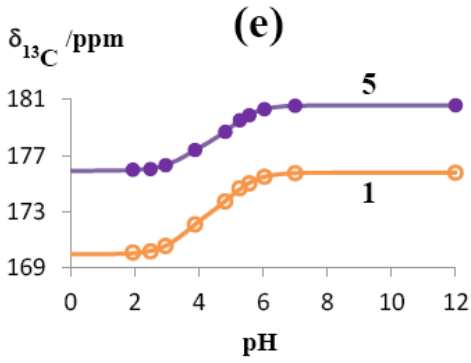

Figure 5: Behavior of chemical shifts of hydrogen and carbon atoms of IA with $\mathrm{pH}$. Markers represent experimental data and lines fitting achieved using Model II in Table 3, obtained in the same procedure, with two pKa values and chemical shifts of nuclei for three different species given in Table 3. (a) Vinylic hydrogen nuceli. (b) Methylene hydrogen nuclei. (c) Vynilic carbon nuclei. (d) Methylene carbon nucleus. (e) Carboxylic carbon nuclei.

Table 2: Results of the Fitting Achieved of Chemical Shifts as a Function of pH for the Different Nuclei of AA and MA with Program HYPNMR to Characterize their Equilibria of Acidity and the Species Involved

\begin{tabular}{|c|c|c|}
\hline Chemical equilibrium & $\mathrm{pK}_{\mathrm{a}}$ & \\
\hline $\mathrm{HL} \leftrightarrows \mathrm{H}^{+}+\mathrm{L}^{-}$ & $4.060 \pm 0.032$ & \\
\hline Position of $\mathrm{H}$ nucleus & $\delta^{1}{ }_{H} / p p m$ in $\mathrm{HL}$ & $\delta^{1}{ }_{\mathrm{H}} / \mathrm{ppm}$ in $\mathrm{L}^{-}$ \\
\hline 3-cis & $6.27 \pm 0.12$ & $5.873 \pm 0.087$ \\
\hline 1 & $170.06 \pm 0.12$ & $175.447 \pm 0.085$ \\
\hline 2 & $127.39 \pm 0.12$ & $133.673 \pm 0.085$ \\
\hline 3 & $133.05 \pm 0.13$ & $126.656 \pm 0.089$ \\
\hline \multicolumn{3}{|c|}{ Methacrylic acid $\left(\sigma_{\text {fitting }}=0.02\right)^{\star \star}$} \\
\hline 3 -cis & $5.913 \pm 0.008$ & $5.493 \pm 0.008$ \\
\hline 3-trans & $5.520 \pm 0.008$ & $5.188 \pm 0.008$ \\
\hline
\end{tabular}




\begin{tabular}{|c|c|c|}
\hline \multicolumn{3}{|c|}{ Methacrylic acid $\left(\sigma_{\text {fitting }}=0.02\right)^{\star *}$} \\
\hline Position of $\mathrm{C}$ nucleus & $\delta^{13} \mathrm{c} / \mathrm{ppm}$ inHL & $\delta^{13} \mathrm{c} / \mathrm{ppm}$ in $\mathrm{L}^{-}$ \\
\hline 1 & $171.615 \pm 0.007$ & $177.410 \pm 0.008$ \\
\hline 2 & $135.875 \pm 0.007$ & $142.246 \pm 0.008$ \\
\hline 3 & $126.970 \pm 0.009$ & $120.376 \pm 0.008$ \\
\hline
\end{tabular}

*Model with one equilibrium of acidity fitting simultaneously 5 sigmoidal curves (one for each nucleus) with 10 points in each one as a function of $\mathrm{pH}$. The data of hydrogen nucleus in position 2 was omitted in the refinement due to the invariance of its chemical shift. Reported pKa $=4.06$ at $25^{\circ} \mathrm{C}[16]$.

${ }^{* *}$ Model with one equilibrium of acidity fitting simultaneously 5 sigmoidal curves (one for each nucleus) with 16 points in each one as a function of $\mathrm{pH}$. The data of hydrogen nucleus in position 4 was omitted in the refinement due to the invariance of its chemical shift. Reported pKa $=4.66$ at $20^{\circ} \mathrm{C}[17]$.

Table 3: Results of the Fitting Achieved of Chemical Shifts as a Function of pH for the Different Nuclei of IA with Program HYPNMR to Characterize their Equilibria of Acidity and the Species Involved

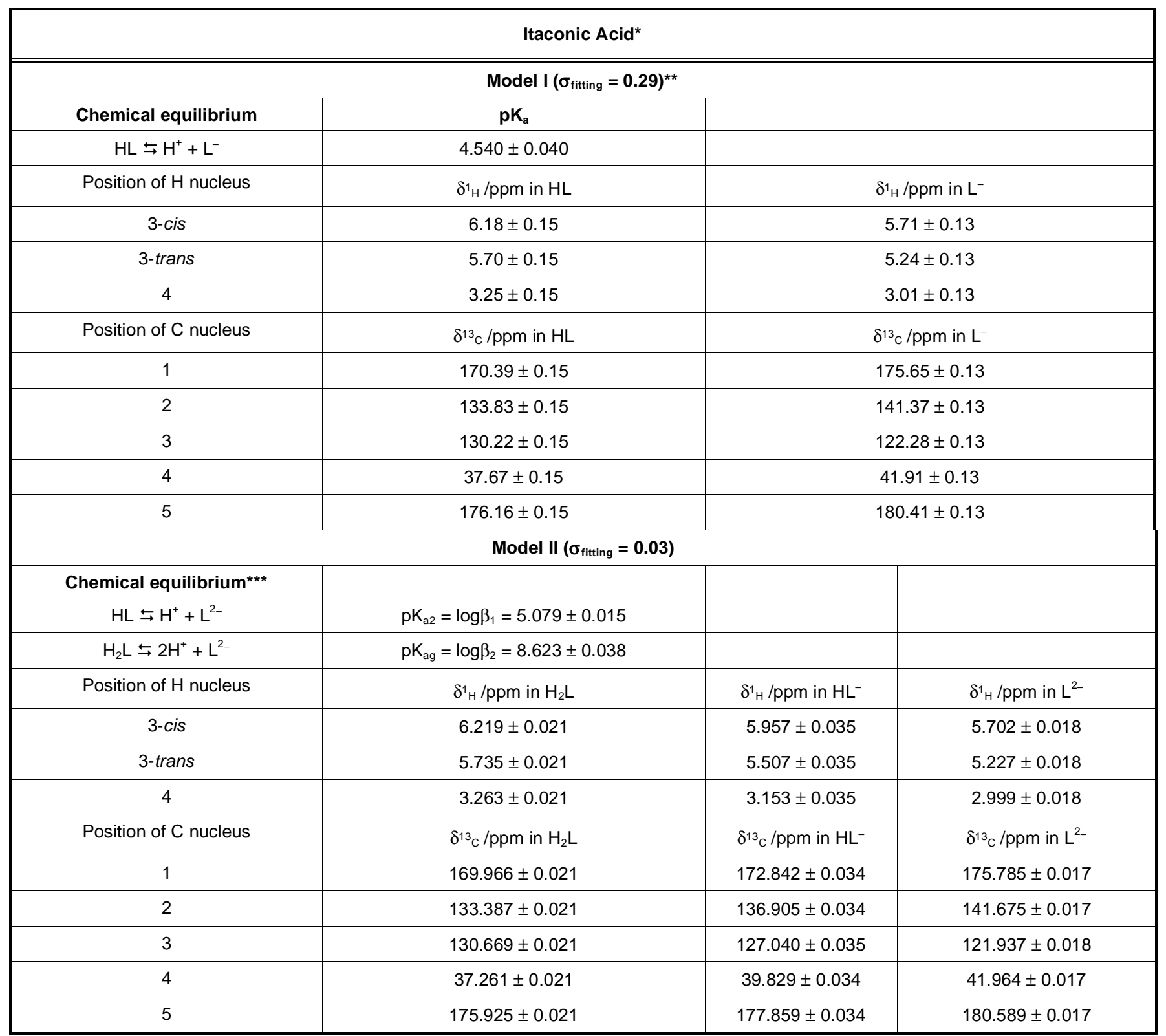

*Models fitting simultaneously 8 sigmoidal curves (one for each nucleus) with 10 points in each one as a function of pH. Model II is the meaningful model with better statistical parameters.

${ }^{* *}$ Meaningless model that has been included only for didactic reasons in discussion.

${ }^{* * *} \mathrm{H}_{2} \mathrm{~L} \leftrightarrows \mathrm{H}^{+}+\mathrm{HL}^{-}: \mathrm{pK}_{\mathrm{a} 1}=\log \beta_{2}-\log \beta_{1}=3.544 \pm 0.041$ and $\mathrm{pK}_{\mathrm{a} 2}=\log \beta_{1}=5.079 \pm 0.015$. Reported values: $\mathrm{pK}_{\mathrm{a} 1}=3.69, \mathrm{pK} \mathrm{a}_{2}=5.22$ at $25^{\circ} \mathrm{C}[9]$. 


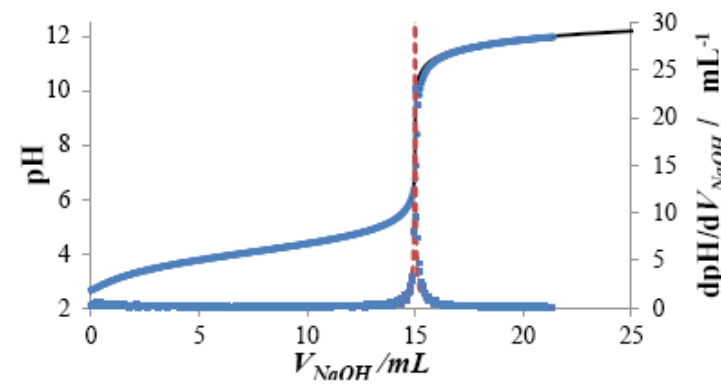

(a)

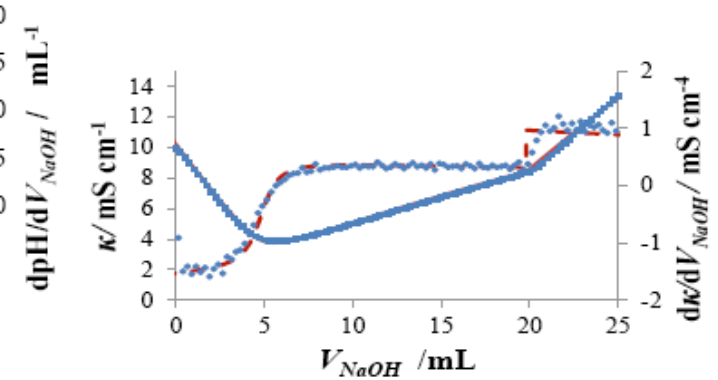

(b)

Figure 6: Titration curves acquired by an automatic titrator. Markers represent experimental points, while solid line represents the fitted curve calculated with a robust model: and segmented line represents the first-derivative of the titration curve, obtained approximately as the quotient of finite differences. (a) Potentiometric titration of $100 \mathrm{~mL}$ aqueous solution of $0.075 \mathrm{M}$ AA with $0.500 \mathrm{M}$ of $\mathrm{NaOH}$. (b) Conductometric titration of $100 \mathrm{~mL}$ aqueous solution of $0.075 \mathrm{M} \mathrm{AA}$ and $0.024 \mathrm{M} \mathrm{HCl}$ with $0.500 \mathrm{M}$ of $\mathrm{NaOH}$. Fitting achieved with $\lambda_{\mathrm{H}^{+}}=340 \mathrm{~S} \mathrm{~cm}^{2} \mathrm{eq}^{-1}, \lambda_{\mathrm{OH}^{-}}=199 \mathrm{~S} \mathrm{~cm}^{2} \mathrm{eq}^{-1}, \lambda_{\mathrm{Na}^{+}}=50 \mathrm{~S} \mathrm{~cm}^{2} \mathrm{eq}^{-1}, \lambda_{\mathrm{Cl}^{-}}=76 \mathrm{~S} \mathrm{~cm}^{2} \mathrm{eq}^{-1}, \lambda_{\mathrm{L}^{-}}=43 \mathrm{~S} \mathrm{~cm}^{2} \mathrm{eq}^{-1}$, and $\mathrm{pK}_{\mathrm{a}}=4.06$.

Then, in all cases only one break is shown in the titration curve $\left(\mathrm{pH}=\mathrm{f}\left(\mathrm{V}_{\mathrm{NaOH}}\right)\right)$, giving a sharp maximum in its first-derivative curve. The points used for $\mathrm{pK}_{\mathrm{a}}$ determination were those before the equivalence point, where there is more information to determine these parameters.

The results obtained for $\mathrm{pK}_{\mathrm{a}}$ values using the program SUPERQUAD are presented in Table 4. These values are in good agreement with those reported previously $[9,16,17]$ and with the $\mathrm{pK}_{\mathrm{a}}$ values determined by HYPNMR, as it is shown in the same Table 4, even though the ionic strength (I) is different for the potentiometric and NMR experiments. The good fitting achieved for the $\mathrm{pK}_{\mathrm{a}}$ values refined with SUPERQUAD is shown in Figures. $\mathbf{6 a}, \mathbf{7 a}$ and $\mathbf{8 a}$ for $A A, M A$ and $I A$, respectively.

Like an additional proof of the good quality of the $\mathrm{pK}_{\mathrm{a}}$ values determined by potentiometric titrations, they have been used to fit conductometric curves of AA, MA or IA with $\mathrm{NaOH}$. These fittings are shown in Figures. $\mathbf{6 b}, \mathbf{7 b}$ and $\mathbf{8 b}$ for $A A, M A$ and $I A$, respectively. The equivalent conductivity used for the fittings are shown in the foot of each Figure and the known values, for $\lambda_{\mathrm{H}^{+}}, \lambda_{\mathrm{OH}^{-}}, \lambda_{\mathrm{Na}^{+}}$and $\lambda_{\mathrm{Cl}^{-}}$, are practically the same that those reported [18] for AA and MA. For IA they show a deviation of approximately $-15 \%$, may be due to the temperature and the ionic strength values of the system in these experiments.

It must be noted that conductometric titration curves for $\mathrm{AA}$ and $\mathrm{MA}$ (Figures $\mathbf{6 b}$ and $\mathbf{7 b}$ ) show almost linear trends (solid line), reflected in its first-derivative curve like almost constants (segmented line).
The first-derivative of the conductometric titration curve for IA (Figure $\mathbf{8 b}$ ) is much more complex before the second equivalence point, due to the fact that $\mathrm{pKa}$ values are near, one of each other; then, the curve in this region is non-linear. Nevertheless, the robust model used to calculate the conductometric curve and the good estimators of $\mathrm{pK}_{\mathrm{a}}$ values allow a very good fitting of experimental curve.

\section{CONCLUSIONS}

In the present work it has been shown that curves of sigmoidal chemical shift (of many nuclei) as a function of $\mathrm{pH}$ may be used to determine $\mathrm{pK}_{\mathrm{a}}$ values on an exact and precise way, using non-linear least squares programs (like HYPNMR) and giving a structural characterization of the system. The values obtained are comparable to those determined by potentiometric methods. This could be an alternative method when the substances under study are very soluble in water.

\section{MATERIALS AND METHODS}

\subsection{NMR Determinations}

\subsubsection{Instrumentation}

Natural abundance spectra were recorded on an AVANCE Bruker 400 spectrometer, operating at 400 $\mathrm{MHz}$ with $\mathrm{PABBO}$ probe. All spectra were acquired at $25^{\circ} \mathrm{C}$.

\subsubsection{Reagents}

$\mathrm{D}_{2} \mathrm{O}$ (Cambridge Isotope Laboratories, Inc.), $\mathrm{KOH}$ (J.T. Baker), $\mathrm{HCl}$ (J.T. Baker), acrylic acid (Dow Chemical), methacrylic acid (Dow Chemical) and itaconic acid (Sigma Aldrich), pH buffers 7, 4 and 10 (Thermo Scientific) and Deionized water. 
Table 4: Comparison of Results for the Acidity Constants $\left(\mathrm{pK}_{\mathrm{a}}\right)$ Obtained by Fitting of Potentiometric Titration Curves or Chemical Shifts/pH Curves for AA, MA and IA with the Aid of Programs SUPERQUAD or HYPNMR, Respectively

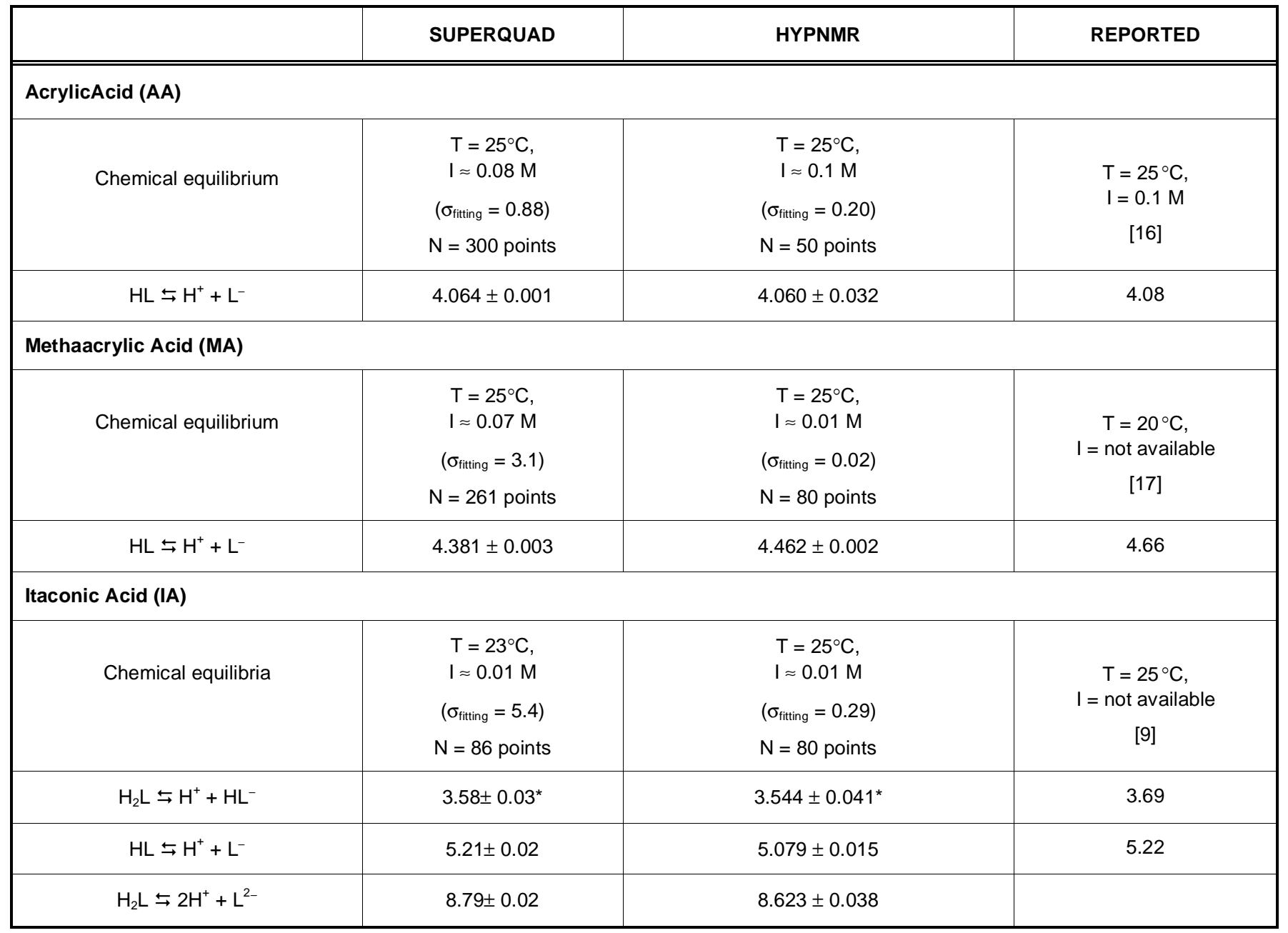

${ }^{*}$ determined by the difference $\log \beta_{2}-\log \beta_{1}$.

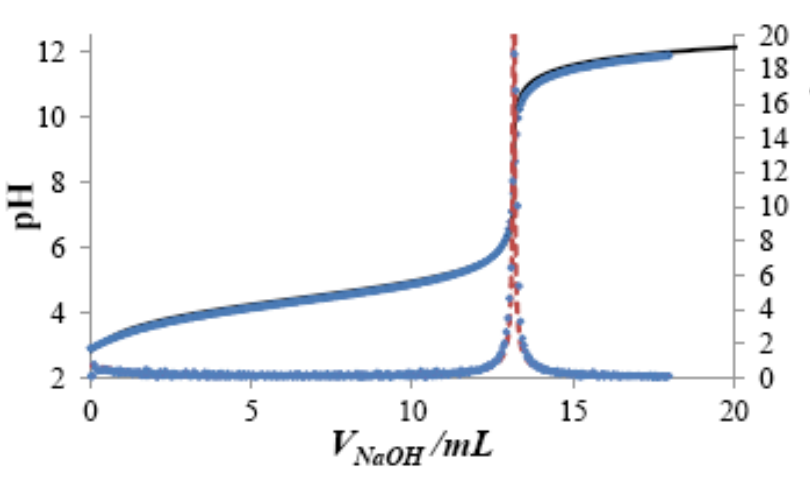

(a)

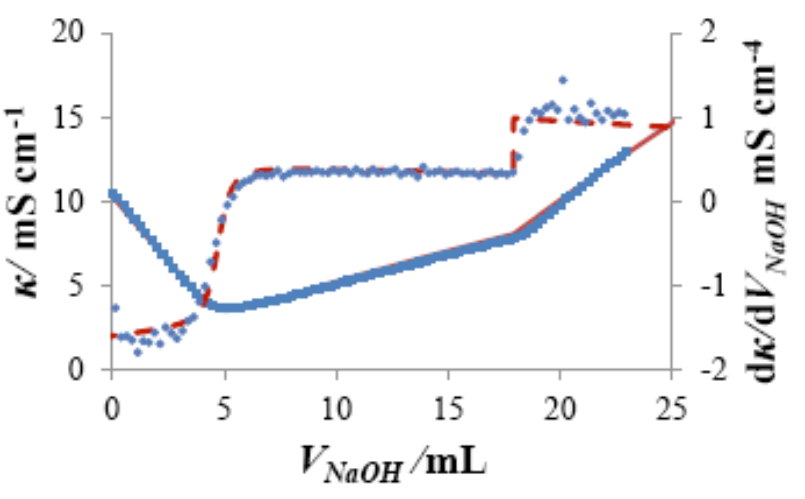

(b)

Figure 7: Titration curves acquired by an automatic titrator. Markers represent experimental points, while solid line represents the fitted curve calculated with a robust model: and segmented line represents the first-derivative of the titration curve, obtained approximately as the quotient of finite differences. (a) Potentiometric titration of $100 \mathrm{~mL}$ aqueous solution of $0.0661 \mathrm{M}$ MA with $0.500 \mathrm{M}$ of $\mathrm{NaOH}$. (b) Conductometric titration of $100 \mathrm{~mL}$ aqueous solution of $0.0661 \mathrm{M} \mathrm{MA}$ and $0.024 \mathrm{M} \mathrm{HCl}$ with $0.500 \mathrm{M}$ of $\mathrm{NaOH}$. Fitting achieved with $\lambda_{\mathrm{H}^{+}}=350 \mathrm{~S} \mathrm{~cm}^{2} \mathrm{eq}^{-1}, \lambda_{\mathrm{OH}^{-}}=199 \mathrm{~S} \mathrm{~cm}^{2} \mathrm{eq}^{-1}, \lambda_{\mathrm{Na}^{+}}=50 \mathrm{~S} \mathrm{~cm}^{2} \mathrm{eq}^{-1}, \lambda_{\mathrm{Cl}^{-}}=76 \mathrm{~S} \mathrm{~cm}^{2} \mathrm{eq}^{-1}, \lambda_{\mathrm{L}^{-}}=45 \mathrm{~S}$ $\mathrm{cm}^{2} \mathrm{eq}^{-1}$, and $\mathrm{pK}_{\mathrm{a}}=4.46$. 


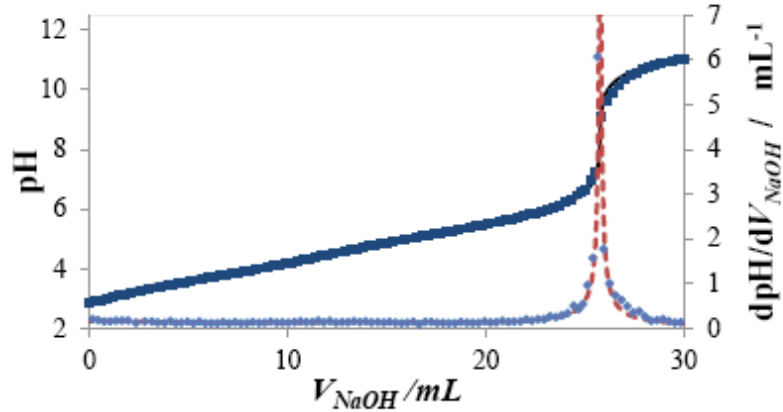

(a)

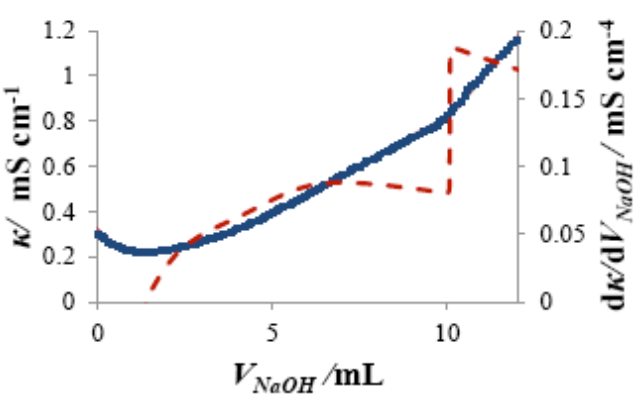

(b)

Figure 8: Titration curves acquired manually. Markers represent experimental points, while solid line represents the fitted curve calculated with a robust model: and segmented line represents the first-derivative of the titration curve, obtained approximately as the quotient of finite differences. a) Potentiometric titration of $100 \mathrm{~mL}$ aqueous solution of $0.0104 \mathrm{M} \mathrm{IA} \mathrm{with} 0.0801 \mathrm{M}$ of $\mathrm{NaOH}$. b) Conductometric titration of $30 \mathrm{~mL}$ aqueous solution of $0.0068 \mathrm{M} \mathrm{AA}$ with $0.0405 \mathrm{M}$ of $\mathrm{NaOH}$. Fitting achieved with $\lambda_{\mathrm{H}^{+}}=315 \mathrm{~S}$ $\mathrm{cm}^{2} \mathrm{eq}^{-1}, \lambda_{\mathrm{OH}^{-}}=165 \mathrm{~S} \mathrm{~cm}^{2} \mathrm{eq}^{-1}, \lambda_{\mathrm{Na}^{+}}=41.8 \mathrm{~S} \mathrm{~cm}^{2} \mathrm{eq}^{-1}, \lambda_{\mathrm{HL}^{-}}=20 \mathrm{~S} \mathrm{~cm}^{2} \mathrm{eq}^{-1}, \lambda_{\mathrm{L}^{2}}=39 \mathrm{~S} \mathrm{~cm}^{2} \mathrm{eq}^{-1}, \mathrm{pK}_{\mathrm{a} 1}=3.83$, and pKa2 $=5.37$.

\subsubsection{Solutions}

$1.0 \mathrm{M} \mathrm{HCl}$ stock solution, diluted with $10 \% \mathrm{D}_{2} \mathrm{O}$ (i.e., $\left.90 \% \mathrm{H}_{2} \mathrm{O}\right)$.

1.0 $\mathrm{M} \mathrm{KOH}$ stock solution, diluted with $10 \% \mathrm{D}_{2} \mathrm{O}$.

$250 \mu \mathrm{L}$ of acrylic acid or methacrylic acid and 9.75 $\mathrm{mL}$ of $10 \% \mathrm{D}_{2} \mathrm{O}$ were mixed well with a small magnetic stir bar and magnetic stirring plate.

$119 \mathrm{mg}$ of itaconic acid with $10 \mathrm{~mL}$ of $10 \% \mathrm{D}_{2} \mathrm{O}$ were mixed well with a small magnetic stir bar and magnetic stirring plate.

The rest of the samples were acquired splitting the work solution (acrylic acid, methacrylic acid or itaconic acid) in two portions, add the $1.0 \mathrm{M} \mathrm{HCl}$ stock solution dropwise to adjust for the lower $\mathrm{pH}$. To the other portion, add $1.0 \mathrm{M} \mathrm{KOH}$ stock solution dropwise to adjust for the higher $\mathrm{pH}$. Various samples were prepared to cover $\mathrm{pH}$ range of approximately $1-13$.

The ionic strength was not imposed to the solutions because in this work it is emphasized the possibility of the determination of pKa values by NMR signals, more than to obtain these values with very high precision.

\subsection{4. $\mathrm{pH}$ Measurements}

$\mathrm{pH}$ values were measured in accord with the procedure ISO 4316 , with a potentiometer 716 DMS Metrohm equipped with a glass combined electrode, 60259.100 Metrohm.

\subsubsection{Spectroscopic Procedures}

Typical one-dimensional ${ }^{1} \mathrm{H}$ and ${ }^{13} \mathrm{C}$ NMR spectra were acquired with standard pulse programs for unequivocal assignment of chemical shifts to nuclei.
Tetramethylsilane (TMS) was used to calibrate chemical shifts of ${ }^{1} \mathrm{H}$ or ${ }^{13} \mathrm{C}$ as internal standard.

\subsection{Titration Determinations with Automatic Titrator}

\subsubsection{Instrumentation}

The potentiometric and conductometric titrations of acrylic, methacrylic or itaconic acid were acquired with Automatic Tritino 808 (Metrohm), equipped with glass combined electrode, 60259.100 Metrohm, (Conductometer 712 Metrohm), Dosing devices (808 and $805 \mathrm{Metrohm}$ ), Exchange unit with data chip of 20 $\mathrm{mL}$, Magnetic stirring plate (804 Metrohm) and TiamoSotware 2.4 (Metrohm).

\subsubsection{Reagents}

$\mathrm{NaOH}$ (J.T. Baker), potassium biphthalate (J.T. Baker), acrylic acid (Dow Chemical), methacrylic acid (Dow Chemical) and itaconic acid (Sigma Aldrich), $\mathrm{pH}$ buffers 7,4 and 10 (Thermo Scientific) and deionized water.

\subsubsection{Solutions}

$0.5 \mathrm{M}$ stock $\mathrm{NaOH}$ solution, $0.01 \mathrm{M} \mathrm{KCl}$ solution.

\subsubsection{Potentiometric Titrations}

The potentiometric titrations were obtained at $25^{\circ} \mathrm{C}$ in a titration vessel filled with $0.5 \mathrm{~g}$ of acid (acrylic, methacrylic or itaconic) and $100 \mathrm{~mL}$ of deionized water, this solution was continuously stirred. Solution of $0.5 \mathrm{M}$ $\mathrm{NaOH}$ was used as titrant. The precise concentration of base was obtained by titrating with primary standard potassium biphtalate. The data of titration were acquired automatically by Tiamo 2.4 Software (Metrohm). 


\subsubsection{Conductometric Titrations}

The conductometric titrations were obtained at 25 ${ }^{\circ} \mathrm{C}$ in a titration vessel filled with $0.5 \mathrm{~g}$ of acid (acrylic, methacrylic or itaconic), a volume of $\mathrm{HCl} 1 \mathrm{M}$ and 100 $\mathrm{mL}$ of deionized water, in order to have an initial $\mathrm{pH}$ near to 2.0 and a narrower beginning of carboxylic acids titration, this solution was continuously stirred. Solution of $0.5 \mathrm{M} \mathrm{NaOH}$ was used as titrant. The precise concentration of base was obtained by titrating with primary standard potassium biphtalate. The data of titration were acquired automatically by Tiamo 2.4 Software (Metrohm).

In both kind of titrations, the ionic strength was also variable.

\subsection{Manual Titrations for IA}

\subsubsection{Instrumentation}

For manual potentiometric titrations a sens ION+ $\mathrm{PH} 31$ potentiometer of Hach was employed, equipped with a 5010T combined electrode with temperature sensor. For conductometric titrations a Radiometer CDM230 conductometer equipped with a CDC641T cell with a constant $\mathrm{H}=1 \mathrm{~cm}^{-1}$ was used.

\subsubsection{Reagents}

$\mathrm{NaOH}$ (J.T. Baker), potassium biphthalate (J.T. Baker), and itaconic acid (Sigma Aldrich), pH buffers 7,4 and 10 (Radiometer) and deionized water.

\subsubsection{Solutions}

$0.5 \mathrm{M}$ stock $\mathrm{NaOH}$ solution, $0.01 \mathrm{M} \mathrm{KCl}$ solution.

\subsubsection{Potentiometric Titrations}

$\mathrm{pH}$-metric titrations were achieved for $\mathrm{IA}$, titrating $100 \mathrm{~mL}$ of $0.0104 \mathrm{M}$ of IA with $0.0810 \mathrm{M}$ of $\mathrm{NaOH}$ at room temperature: $(23.00 \pm 0.50)^{\circ} \mathrm{C}$. Calibration was achieved by a method reported previously, considering the electrochemical cell efficiency $[19,20]$.

\subsubsection{Conductometric Titrations}

Conductometric titrations were achieved for IA, titrating $30 \mathrm{~mL}$ of $0.0068 \mathrm{M}$ of $\mathrm{IA}$ with $0.0405 \mathrm{M}$ of $\mathrm{NaOH}$ at room temperature: $(22.60 \pm 0.63)^{\circ} \mathrm{C}$.

In both kind of titrations, the ionic strength was also variable.

\section{ACKNOWLEDGEMENTS}

We acknowledge Prof. Peter Gans by the copy of program HYPNMR and Prof. Alberto Vacca by the copy of program SUPERQUAD, both used to fit the curves obtained in the present work. NR-L acknowledge CONACyT and AS-H acknowledge FESE-COMEX by stipends given to undertake this work.

\section{REFERENCES}

[1] Teramoto N, Shigehiro O, Ogawa Y, Maruyama Y, Shimasaki T, Shibata M. Polymer foam-reinforced hydrogels inspired by plant body frameworks as high-performance soft matter. Polymer J 2014; 46: 592-7. http://dx.doi.org/10.1038/pj.2014.41

[2] Krušić MK, Filipović J. Copolymer hydrogels based on Nisopropylacrylamide and itaconic acid. Polymer 2006; 47: 148-55.

http://dx.doi.org/10.1016/j.polymer.2005.11.002

[3] Dvořáčková $K$, Doležel $P$, Mašková $E$, Muselík J, Kejdušová $\mathrm{M}$, Vetchý $\mathrm{D}$. The effect of acid $\mathrm{pH}$ modifiers on the release characteristics of weakly basic drug from hydrophliliclipophilic matrices. AAPS PharmSciTech 2013; 14: 1341-8. http://dx.doi.org/10.1208/s12249-013-0019-1

[4] Koo H-J, So J-H, Dickey MD, Velev OD. Towards all-soft matter circuits: Prototypes of quasi-liquid devices with memristor characteristics. Adv Mater 2011; 23:3559-64. http://dx.doi.org/10.1002/adma.201101257

[5] Zohra R, Malana MA, Iqbal Z. Formulation, characterization study of swelling kinetics and network parameters of Poly (MA-co-VA-co-AA) terpolymeric hydrogels with various concentrations of acrylic acid. J Res Updates Pol Sci 2013; 2: $142-52$

[6] Kim S, Kim JY, Huh KM, Acharya G, Park K. Hydrotropic polymer micelles containing acrylic acid moieties for oral delivery of paclitaxel. J Control Rel 2008; 132: 222-9. http://dx.doi.org/10.1016/j.jconrel.2008.07.004

[7] Bezençon J, Wittwer MB, Cutting B, Smieško M, Wagner B Kansy $\mathrm{M}$, Ernst $\mathrm{B}$. $\mathrm{pK}_{\mathrm{a}}$ determination by ${ }^{1} \mathrm{H}$ NMR spectroscopy - An old methodology revisited. J Pharm Biomed Anal 2014, 93: 147-55.

http://dx.doi.org/10.1016/j.jpba.2013.12.014

[8] Rodríguez-Barrientos D, Rojas-Hernández A, Gutiérrez A Moya-Hernández R, Gómez-Balderas R, Ramírez-Silva MT. Determination of $\mathrm{pK}_{\mathrm{a}}$ values of tenoxicam from ${ }^{1} \mathrm{H}$ NMR chemical shifts and of oxicams from electrophoretic mobilities (CZE) with the aid of programs SQUAD and HYPNMR. Talanta 2009; 80: 754-76.

http://dx.doi.org/10.1016/j.talanta.2009.07.058

[9] De Robertis A, De Stefano C, Rigano C, Sammartano S. Thermodynamic parameters for the protonation of carboxylic acids in aqueous tetraethylammoniun iodide solutions. J Solution Chem 1990; 19: 569-87.

http://dx.doi.org/10.1007/BF00647030

[10] Frassineti Ch, Ghelli S, Gans P, Sabatini A, Moruzzi MS Vacca A. Nuclear Magnetic Resonance as a tool for determining protonation constants of natural polyprotic bases in solution. Anal Biochem 1995; 231: 374-82.

[11] FrassinetiCh, Alderighi L, Gans P, Sabatini A, Vacca A Ghelli S. Determination of protonation constants of some fluorinated polyamines by means of ${ }^{13} \mathrm{C}$ data processed by the new computer program HypNMR2000. Protonation sequence of polyamines. Anal Bioanal Chem 2003; 376: 1041-52.

http://dx.doi.org/10.1006/abio.1995.9984

[12] Asuero A, Michałowski T. Comprehensive formulation of titration curves for complex acid-base systems and its analytical implications. Crit Rev Anal Chem 2011; 41: 15187.

http://dx.doi.org/10.1007/s00216-003-2020-0

[13] Rojas-Hernández A, Rodríguez-Laguna N, Ramírez-Silva MT, Moya-Hernández R. Distribution diagrams and graphical 
methods to determine or to use the stoichiometric coefficients of acid-base and complexation reactions. In: Innocenti A, editor. Stoichiometry and research. The importance of quantity in biomedicine. Rijeka: InTech, 2011; p. 287-310. Available from: http://cdn.intechopen.com/pdfs-wm/30991.pdf

[14] Gans P, Sabatini A, Vacca A. SUPERQUAD: an improved general program for computation of formation constants from potentiometric data. J Chem Soc Dalton Trans 1985; 1195200.

http://dx.doi.org/10.1039/dt9850001195

[15] Hoye TR, Zhao H. A Method for easily determining coupling constant values. J Org Chem 2002; 67: 4014-6. http://dx.doi.org/10.1021/j0001139v

[16] De Stefano C, Gianguzza A, Piazzese D, Sammartano S. Polyacrylite protonation in various aqueous ionic media at different temperatures and ionic strengths. J Chem Eng Data 2000; 45: 876-81.

http://dx.doi.org/10.1021/je0000219
[17] Organization for Economic Co-operation and Development. Screening Information Data Sets. Methacrylic Acid Initial Assessment Profile. United Nations Environment Program Publications 2006. Available from: http://www.chem.unep.ch/irptc/sids/OECDSIDS/79414.pdf

[18] Bard AJ, Faulkner LR. Electrochemical methods. Fundamentals and applications. New York: Wiley 1980; ( $p$ 66.)

[19] Islas-Martínez JM, Rodríguez-Barrientos D, Galano A, et al. Deprotonation mechanism of new antihypertensive piperidinyl methylphenols: a combined experimental and theoretical study J Phys Chem B 2009; 113: 11765-74. http://dx.doi.org/10.1021/jp904474m

[20] Sanpedro-Montoya K, Martínez-Pérez B, Galano A, et al. Deprotonation mechanism and $\log P$ values of new antihypertensive thiomorpholinyl methylphenols: a combined experimental and theoretical study. J Chem Eng Data 2010; 55: 4323-31.

http://dx.doi.org/10.1021/je100470g

(c) 2015 Ibarra-Montaño et al.; Licensee Lifescience Global.

This is an open access article licensed under the terms of the Creative Commons Attribution Non-Commercial License (http://creativecommons.org/licenses/by-nc/3.0/) which permits unrestricted, non-commercial use, distribution and reproduction in any medium, provided the work is properly cited. 